\title{
Improving prospects for employment of the haemophiliac
}

\author{
JOHN STUART, CHARLES D FORBES, PETER JONES, GEOFFREY LANE, \\ CHARLES R RIZZA, SUSAN WILKES
}

The recent introduction of self-treatment has dramatically improved the management of severe haemophilia $A$ and $B$ (Christmas disease), and most sufferers in Britain can now inject themselves intravenously with factor VIII or IX concentrate whenever they suspect bleeding. ${ }^{1}$ This change in management has reduced dependence on hospital treatment, increased social independence and morale, ${ }^{2}$ and possibly will delay, if not prevent, the development of chronic haemophilic arthropathy. ${ }^{3}$ The potential effect, however, of this advance on employment prospects has yet to be determined.

In previous studies on the employment of haemophiliacs ${ }^{4}$ the reported incidence of unemployment varied from $18 \%$ to $35 \%$ compared with a national unemployment rate of around $7 \%$. It might be expected that improved treatment would increase employment prospects and help offset the approximate cost of $£ 2000$ a patient a year for purchasing blood product concentrate. We describe a study of the factors that currently affect the employment prospects of the haemophiliac, together with an assessment of the impact of self-treatment.

\footnotetext{
Department of Haematology, Queen Elizabeth Hospital, Edgbaston, Birmingham B15 2TH

JOHN STUART, MD, FRCPATH, professor
}

Department of Medicine, Royal Infirmary, Glasgow

CHARLES D FORBES, MD, FRCP, senior lecturer

Newcastle Haemophilia Centre, Royal Victoria Infirmary, Newcastle upon Tyne NE1 4LP

PETER JONES, MD, FRCP, consultant paediatrician

Travenol Laboratories Ltd, Thetford, Norfolk 1P24 3SE

GEOFFREY LANE, BA, systems analyst

Oxford Haemophilia Centre, Churchill Hospital, Oxford 0X3 7BP CHARLES R RIZZA, MD, FRCP, consultant physician

Employment Medical Advisory Service, McLaren Building, Birmingham B4 7NP

SUSAN WILKES, BA, SRN, research officer

\section{Methods}

In 1978 a study group on employment was established by the Home Therapy Working Party of the United Kingdom Haemophilia Centre Directors. Members of staff of four haemophilia centres (Birmingham, Glasgow, Newcastle, and Oxford) participated and sent questionnaires to 636 patients with all degrees of severity of haemophilia A and B aged from 16 to 65 . The questionnaire had five main sections with which it was hoped to determine:

(1) Severity of haemophilia and the patient's general qualifications for employment.

(2) Details of present employment.

(3) Influence of self-treatment at work.

(4) Details of previous employment of those who were unemployed at the time of the study.

(5) What career advice and help patients had received.

The doctor in charge of each patient's treatment was asked to give details of diagnosis and severity, and to state whether or not there was some other medical condition likely to affect employment prospects. To ensure confidentiality, all patients were identified by a code known only to the doctor in charge at each participating centre. The data from the completed questionnaires were processed on an IBM 34 computer and the results analysed both by region and by three grades of severity (severe: coagulant activity factor level $<1$ unit $/ \mathrm{ml}$; moderate: $1-5$ units $/ \mathrm{ml}$; mild: $>5$ units $/ \mathrm{ml}$ ).

When a comparison was made between haemophiliacs and the general population the distribution was assumed to be binomial and, depending on the sample size, the confidence levels were determined using Poisson or $t$-test approximations to the binomial distribution. When a comparison was made between groups of haemophiliacs, the $\chi^{2}$ test was used. The statistical test used is shown against each $p$ value in the text.

\section{Results}

Of the 636 questionnaires posted, $79 \%$ were returned for analysis. Altogether 429 patients $(86 \%)$ suffered from haemophilia A, 66 $(13 \%)$ from haemophilia $B$, and seven $(1 \%)$ were undefined. There was a preponderance of young people $(59 \%$ between 16 and 35 (table I)). The severity was as follows: severe $243(48 \%)$, moderate $120(24 \%)$, 
and mild $139(28 \%)$. Thirty-seven per cent were on self-treatment, half of them for at least three years. Analysis of marital state showed a significant reduction ( $t$ test; $p<0.01$ ) in marriage rate in the $26-45-$ year age groups, suggesting that severe haemophiliacs tend to marry later in life than the general population.

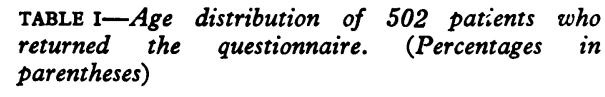

\begin{tabular}{ccc}
\hline Age (yr) & All patients & $\begin{array}{c}\text { Patients on } \\
\text { self-treatment }\end{array}$ \\
\hline & & \\
$16-25$ & $180(36)$ & $87(46)$ \\
$26-35$ & $115(23)$ & $48(26)$ \\
$36-45$ & $100(20)$ & $34(18)$ \\
$46-55$ & $58(12)$ & $12(6)$ \\
$56-65$ & $38(7)$ & $3(2)$ \\
No age given & $11(2)$ & $4(2)$ \\
\hline & 502 & 188 \\
\hline
\end{tabular}

Nearly half $(48 \%)$ of the haemophiliacs had registered as disabled with the Department of Employment, this trend accelerating in the past decade with the general increase in unemployment. Of the unemployed haemophiliacs, $39 \%$ had attended a Governmentsponsored rehabilitation centre, but most found it of no value. Very few of the 502 patients had any additional medical problems that would have militated against employment: five reported epilepsy, and there were individual cases of asthma, ulcerative colitis, chronic liver disease, and multiple sclerosis.

\section{EDUCATION}

The frequent bleeds associated with severe haemophilia used to have a major adverse effect on education. Analysis of all respondents in this study showed that $55 \%$ had lost more than one month of schooling a year, this figure rising to $77 \%$ in the severely affected group. Table II shows a comparison between 96 severely affected patients aged 16-25 and 62 severely affected patients aged 26-35.

TABLE II-Estimated schooling missed per year by two age groups of severely affected patients. (Percentages in parentheses)

\begin{tabular}{ccc}
\hline Weeks lost & $16-25$ years & $26-35$ years \\
\hline$>8$ & $38(40)$ & $39(63)$ \\
$3-8$ & $43(45)$ & $21(34)$ \\
$<2$ & $15(15)$ & $2(3)$ \\
\hline & 96 & 62 \\
\hline
\end{tabular}

There was a significant reduction $\left(\chi^{2}\right.$ test; $\left.p<0.01\right)$ in the amount of schooling lost a year in the younger group.

Most respondents had attended a normal school, but $98(17 \%)$ had attended a school for the physically handicapped and $7 \%$ had also received home tuition. More of the severely affected patients $(27 \%)$ had attended a school for the physically handicapped.

When academic achievements were analysed by age there was a significant increase $\left(\chi^{2}\right.$ test; $\left.p<0 \cdot 001\right)$ in the number of young patients (16-25 years) with qualifications (Certificate of Secondary Education, "O," or " $A$ " levels); this increase was unrelated to clinical severity. Half of all respondents had attempted courses of further education, the proportion going to different types of educational establishment being similar in the different severity groups. A university degree had been obtained by $7 \%$ of the 502 patients. Trade apprenticeships seemed to be less popular with severely affected haemophiliacs $(9 \%)$ than with mildly affected patients $(29 \%)$.

\section{EMPLOYMENT}

The overall unemployment rate for haemophiliacs was $17.5 \%$ compared with a United Kingdom rate of $6.9 \%$ at the time of the survey. Unemployment was more common in severely affected patients: $\mathbf{9 \cdot 4} \%$ of mild haemophiliacs were unemployed compared with $18.8 \%$ of moderately severe and $21.7 \%$ of severely affected patients (table III). The difference in unemployment rate between mildly affected patients and the others is significant $\left(\chi^{2}\right.$ test; $\left.p<0.01\right)$ and was found in each of the four regions. There was, however, a pronounced regional variation in unemployment rates (table III).

Of the 368 employed patients, $76 \%$ had been in their present job for more than three years and half for more than 10 years. Most $(70 \%)$ had originally obtained a job on their own initiative, and indeed $75 \%$ considered that they had received no advice leading to employment from either their haemophilia centre staff, school teacher, youth employment or careers officer, or disablement resettlement officer.

TABLE III-Unemploymen

\begin{tabular}{|c|c|c|c|c|c|}
\hline & \multirow{2}{*}{$\begin{array}{c}\text { General } \\
\text { population }\end{array}$} & \multicolumn{3}{|c|}{$\begin{array}{l}\text { Coagulation defect: severity } \\
\text { (factor level, units/ml) }\end{array}$} & \multirow{2}{*}{ Totals } \\
\hline & & $<1$ & $1-5$ & $>5$ & \\
\hline $\begin{array}{l}\text { Birmingham } \\
\text { No unemployed } \\
\text { Sample size } \\
\text { Unempl rate (\%) } \\
\text { Glasgow }\end{array}$ & $6 \cdot 2$ & $\begin{array}{l}9 \\
63 \\
14 \cdot 3\end{array}$ & $\underset{4 \cdot 3}{1}$ & 31 & $\begin{array}{c}11 \\
117 \\
9 \cdot 4\end{array}$ \\
\hline $\begin{array}{l}\text { No unemployed } \\
\text { Sample size } \\
\text { Unempl rate (\%) } \\
\text { Newcastle }\end{array}$ & 8.8 & $\begin{array}{c}4 \\
9 \\
44 \cdot 4\end{array}$ & $\begin{array}{l}15 \\
35 \\
42 \cdot 9\end{array}$ & $\begin{array}{l}5 \\
39 \\
12 \cdot 8\end{array}$ & $\begin{array}{l}24 \\
83 \\
28 \cdot 9\end{array}$ \\
\hline $\begin{array}{l}\text { No unemployed } \\
\text { Sample size } \\
\text { Unempl rate (\%) } \\
\text { Oxford }\end{array}$ & $9 \cdot 7$ & $\begin{array}{l}16 \\
51 \\
31 \cdot 4\end{array}$ & $\begin{array}{l}5 \\
26 \\
19 \cdot 2\end{array}$ & $\begin{array}{l}4 \\
31 \\
12 \cdot 9\end{array}$ & $\begin{array}{c}25 \\
108 \\
23 \cdot 1\end{array}$ \\
\hline $\begin{array}{l}\text { No unemployed } \\
\text { Sample size } \\
\text { Unempl rate }(\%) \\
\text { Total }\end{array}$ & $7 \cdot 4$ & $\begin{array}{l}16 \\
84 \\
19 \cdot 0\end{array}$ & $\begin{array}{r}0 \\
28 \\
0\end{array}$ & $\begin{array}{c}2 \\
26 \\
7 \cdot 7\end{array}$ & $\begin{array}{c}18 \\
138 \\
13 \cdot 0\end{array}$ \\
\hline $\begin{array}{l}\text { No unemployed } \\
\text { Sample size } \\
\text { Unempl rate (\%) }\end{array}$ & 6.9 & $\begin{array}{c}45 \\
207 \\
21 \cdot 7\end{array}$ & $\begin{array}{c}21 \\
112 \\
18.8\end{array}$ & $\begin{array}{l}12 \\
127 \\
9 \cdot 4\end{array}$ & $\begin{array}{c}78 \\
446 \\
17 \cdot 5\end{array}$ \\
\hline
\end{tabular}

The unemployment rate for all haemophiliacs in Glasgow $(p<0.001)$, Newcastle $(\mathrm{p}<0.001)$, and Oxford $(\mathrm{p}<0.05)$ is significantly /higher than that in the genera population. In Birmingham ( $p>0.1$ ) the unemployment rate of $9.4 \%$ is not The number of unemployed severe haemolation.

The number of unemployed severe haemophiliacs is significantly higher $(p<0.01)$ han the general population in all four regions as well as for the total sample.

employment rate for those with moderate haemophilia is not much lower than that for severe haemophilia, the rate for mild haemophiliacs is not significantly higher $(p>0.15)$ than the total United Kingdom unemployment rate. $P$ values determined using Poisson distribution.

Most $(89 \%)$ of those employed reported no difficulty with the hours worked or with the amount of standing, transport to or from work, or other factors concerned with the job itself. Sixty-six per cent travelled to work by car, most living within a short distance of their employment, and $15 \%$ travelled by public transport. Almost all $(90 \%)$ appeared to be satisfied with their employment and had not requested any special privileges. Despite this, one-quarter felt that their job was unsuitable for a haemophiliac because of heavy physical work and a risk of cuts and bruises. When asked, however, about the frequency and cause of bleeding, it was evident (table IV) that most accidents precipitating bleeding were impact injuries with doors or furniture, or falls, rather than injuries caused by heavy work or machinery. On average, less than one bleed a month was considered to have developed at work, and few bleeds appeared to result as a direct consequence of travel to and from work whether this was by car, bus, or foot.

TABLE IV-Accidents occurring at work

\begin{tabular}{lr}
\hline Knocks against doors and office furniture & $34(32 \%)$ \\
Falls caused by tripping or slipping & $28(27 \%)$ \\
Strains caused by heavy work & $16(15 \%)$ \\
Cuts caused by machinery, etc & $12(11 \%)$ \\
Jerks and twists & $9(9 \%)$ \\
Falling objects & $6(6 \%)$ \\
\hline
\end{tabular}

The high unemployment rate for haemophilic patients has resulted in a natural tendency to hide the diagnosis, and one-quarter of the patients had not told their employer of their disorder. In contrast, $79 \%$ of those who took the employer into their confidence considered that the employer was either "very" or "reasonably" helpful; $72 \%$ of haemophiliacs had told their workmates and in $80 \%$ of cases considered that this had been of benefit. In the unemployed group 
$30 \%$ always, and $25 \%$ sometimes, failed to state that they had haemophilia at interview, $76 \%$ feeling that they had failed to get appointments because of their disorder.

\section{SOCIOECONOMIC STATE}

When socioeconomic grouping was studied it was evident that the employment state of the patients was broadly similar to the population of the United Kingdom, although the percentage of patients employed in manual work $(55.2 \%)$ was significantly higher ( $t$ test; $\mathrm{p}<0.001)$ than the general population $(39.1 \%)$. There was, however, a significant increase in skilled manual workers among the haemophiliacs ( $t$ test; $\mathrm{p}<0.001$ ), and also in the group intermediate between professional and skilled non-manual workers ( $t$ test; $\mathrm{p}<0.01$ ).

\section{EFFECT OF HOME TREATMENT}

Of the 502 patients studied, $188(37 \%)$ were on self-treatment and of these, $167(88 \%)$ were severely affected. The results obtained from the 243 severely affected patients have been analysed separately to see if any trends attributable to self-treatment have yet emerged.

Of the 97 severely affected patients aged $16-25,78(80 \%)$ were on self-treatment compared with 14 of the $36(39 \%)$ aged 46 to 65 . Half of these severely affected patients had been on a self-treatment programme for more than three years. A highly significant improvement in mobility was found in the self-treatment group, with significantly more having a driving licence $\left(\chi^{2}\right.$ test; $\left.p<0.001\right)$ or owning a motor vehicle ( $\chi^{2}$ test $\left.; p<0.05\right)$. There were no significant differences in the groups in terms of physical disability. There was a highly significant improvement in school attendance for the 16-25-year age group as a whole, with no difference $\left(\chi^{2}\right.$ test; $\left.p>0 \cdot 5\right)$ between the self-treatment group and others receiving on-demand treatment at hospital.

These results probably reflect the general increase in standard of care. As a result of better attendance at school, academic standards, as judged by achievement of examination certificates, have improved for the 16-25-year-olds compared with the older age groups, but no additional beneficial effect has yet to be seen in the self-treated. When the number undertaking further education is examined separately, however, a highly significant $\left(\chi^{2}\right.$ test; $\left.p<0.01\right)$ improvement in achievement is evident for those on self-treatment.

Thirty-seven per cent of patients considered that the introduction of home treatment had allowed them to continue in their present post, $8 \%$ had been able to return to work, and $31 \%$ considered that their potential range of work had increased. Of the 188 patients on self-treatment, however, only 36 actually administered concentrate while at work, the benefits of self-treatment largely resulting from earlier treatment at home, with consequent improved mobility and reduced convalescence time after a bleed. Some of the patients even returned home from work to administer concentrate. Only $49 \%$ of workplaces had a first-aid room; $30 \%$ had a works nurse and $23 \%$ a works doctor.

Of those patients who treated themselves at work, $79 \%$ left a treatment kit behind overnight, $74 \%$ storing their unused, sealed concentrate packs in a refrigerator. In $58 \%$ of these cases the refrigerator also contained food. Injections were usually administered in the first-aid room $(40 \%)$ or office $(31 \%)$, and $43 \%$ of patients said that they gave their intravenous injection without anyone else being present in case of difficulty. In two cases a kitchen had been used for injections. Twenty-six per cent of those giving injections disposed of their equipment at work, rather than taking used materials home.

\section{Discussion}

The results of this survey again emphasise the major social problems of the patient with haemophilia. Recent advances in management and the effect of the widespread availability of clotting factor concentrates needed for treatment have not yet been fully realised by the public, potential employers, or administrative bodies concerned with careers guidance. In the past, recurrent bleeding resulted in significant loss of schooling and academic underachievement, and there is still a widely held view that haemophiliacs remain poorly educated, cannot undertake skilled or manual employment, and bleed catastrophically on minor injury. The results of this survey have shown that, despite inadequate treatment and schooling in the past, haemophiliacs of working age can achieve surprisingly good socioeconomic and employment standards. Older patients have often retained sufficient motivation to undertake a course of further education and, once in work, prove to be loyal, reliable, and dependable employees. Although one-quarter of employed haemophiliacs thought their job to be less than ideal for a person with a bleeding disorder, most reported no major difficulty at work and had not asked for any privilege. This attitude probably reflects the patients' wish to minimise "handicap." It also reflects the helpful attitude of employers and workmates. The few bleeds (usually less than one a month) that occurred at work or during associated travel were often the result of the unavoidable slips and knocks of daily life.

It is interesting to note the increase in academic achievement among younger, severely affected patients (particularly those on self-treatment), and it will be interesting to see how patients who have used home treatment from a very early age fare when they come of age to seek employment. The advantages of selftreatment at work, as well as at home, are of great importance to patient and employer. The minimum of time is lost as a result of minor injury at the cost of a very occasional 15-minute break in order to administer clotting factor concentrate. Indeed. $75 \%$ of patients suffered less than one bleed a month at work and $70 \%$ reported no bleeds at work that had required urgent treatment in the previous year. This point, and the fact that nearly $76 \%$ of the group studied had been in the same job for more than three years, are probably two of the most important pieces of information to come from this study and should be made known to all potential employers. The informed employer is obviously helpful and, provided employment agencies ensure that more potential employers become well informed, the haemophiliac should be encouraged to disclose his condition at interview and to emphasise how well he copes with it. In doing so he will have the backing of his haemophilia reference centre staff who, when required, are always willing to speak to potential employers and to give any necessary references or medical reports in confidence and with the permission of the patient. With this in mind haemophilia centre directors should now encourage more of their patients to extend self-treatment at home to self-treatment at work. Although $69 \%$ of severely affected haemophiliacs in this study were on self-treatment, only $20 \%$ of them treated themselves at work. One explanation for this discrepancy may be that the haemophiliac is reluctant to ask for special privileges, even though these would be minimal.

Legislation to provide special facilities or jobs is not required since previous generations of haemophiliacs, once employed, have achieved near parity with the United Kingdom average in job achievement. Now that self-treatment has narrowed the clinical gap between mildly and severely affected patients, the emphasis should be to reduce the unemployment rate of the severely affected haemophiliac from three times the national average to the comparable figure already achieved by the mildly affected patient.

For those who are unemployed, particularly in the north of the country, the picture remains gloomy. Despite registration as disabled, the availability of training schemes, and the disablement resettlement service, the chances of employment fall rapidly with age. The psychological effects of unemployment are great ${ }^{8}$ and are often associated with personality disorders, which in turn reduce the chances of employment. It is sad to see how little impact has so far been made by the medical and social professions on the problem of unemployment in haemophilia when such dramatic improvements have been made in the medical aspects of the disorder. To try to improve this position one of the remits of the present working party was to prepare information booklets for both haemophiliacs and potential employers to disseminate the knowledge gained from the study. The booklets will be distributed by the haemophilia 
centre directors of the United Kingdom and by the Manpower Services Commission.

We are indebted to A Cowell, R L Goodyer, I D Marshall, J L Prothero, and J H Quin for their help in preparing this report, and to Travenol Laboratories for a research grant for computing, statistical, and printing costs. Much helpful advice was given by Dr F C Edwards of the Employment Medical Advisory Service, Birmingham, and P V McDonald Clark of Imperial Metal Industries, Ltd.

Reprints may be obtained from Professor Stuart. Copies of the questionnaire used in the study are available from any of the four participating haemophilia centres. The booklet on employment for haemophiliacs may be had from the Haemophilia Society, PO Box 9, 16 Trinity Street, London SE1 1DE.

\section{References}

1 Jones P, Fearns M, Forbes C, Stuart J. Haemophilia A home therapy in the United Kingdom 1975-76. Br Med F 1978;i:1447-50.

2 Ingram GIC, Dykes SR, Creese AL, et al. Home treatment in haemophilia: clinical, social and economic advantages. Clin Lab Haematol 1979; 13-27.

${ }^{3}$ Levine PH. Efficacy of self-therapy in hemophilia. $N$ Engl $₹$ Med 1974; $291: 1381-4$

4 Prothero J. Haemophilia society survey. London: Haemophilia Society, 1977.

5 Markova I, Lockyer R, Forbes CD. Haemophilia : a survey on social issues. Health Bull 1977;35:177-82.

- Markova I, Forbes C. Haemophilia: a study into social and psychological problems. Health Bull 1977;37:24-9.

(Accepted 6 March 1980)

\title{
Medical research: civil liability and compensation for personal injury-a discussion paper
}

\author{
CIBA FOUNDATION STUDY GROUP
}

\section{Summary and conclusions}

The Ciba Foundation Study Group has considered the most appropriate means of compensating participants (or their relatives) for injuries received as a consequence of medical research. The group recognises that injury may occur despite the exercise of the highest degree of skill and care by the investigator and that compensation through an action for negligence is therefore not available. At present injured participants have to rely on ex gratia payments. The group considers this unsatisfactory and recommends the establishment of a centrally operated fund with authority to provide compensation on a no-fault basis.

These recommendations do not diminish the rights of the participant to bring an action in the event of negligence on the part of the investigator or an action under the law relating to product liability against the manufacturers of defective equipment or drugs.

\section{Introduction}

Research is essential to the practice of medicine, and its main aim is to promote discoveries that will improve the health of the community. It has made an important contribution to increasing

Members of the Ciba Foundation Study Group were: $T$ Binns, senior lecturer in pharmacology and therapeutics, London Hospital; L H Blumgart, professor of surgery, Hammersmith Hospital, London; A Diamond, director, Institute of Advanced Legal Studies, University of London; C T Dollery, professor of clinical pharmacology, Royal Postgraduate Medical School, London; R H T Edwards, professor of human metabolism, University College Hospital Medical School, London; D C Evered, director, Ciba Foundation, London; R Huws Jones, formerly principal, National Institute for Social Work; D R Laurence, professor of clinical pharmacology, University College Hospital Medical School, London; J K Lloyd, professor of child health, St George's Hospital Medical School, London; R Porter, deputy director, Ciba Foundation, London; Sir Charles Wilson, formerly principal and vice-chancellor, University of Glasgow. life expectancy at all ages and reducing the burden of many distressing, but non-fatal, diseases. The research needed for these and other medical advances has followed various routes. Some advances in medical knowledge have had their origin in purely laboratory experiments-in physics, chemistry, biology, and many other disciplines; others have originated from observations made on living organisms-bacteria, animals, and humans, particularly those with disease. The development of many successful lines of medical research has required contributions from a wide range of scientific disciplines, but an essential and final stage in the development of any new treatment or technique which may benefit the health of the community is research in human beings.

\section{Research in man}

Medical research in humans is conducted in one of two ways. Firstly, it may be carried out by observation, without interference with the subject. Secondly, it may be carried out by ethical human experiments in which the internal or external environment of an individual or group of individuals is altered under controlled conditions to make quantifiable observations. The important distinction between observation and experiment is that some risk of personal injury or even death is unavoidable in human experiments, even though every care is taken. Serious accidents causing harm or death are extremely uncommon, but they do occur and this is a matter of real concern for those who conduct experiments in humans. All institutions undertaking research on human subjects in the United Kingdom now possess an ethical committee whose function is to scrutinise proposals for research in man. This procedure generally works well and provides a reasonable compromise between protecting the participant in the experiment and avoiding a complex bureaucratic mechanism which would impede beneficial research.

If an accident occurs, the present legal position is that the individual who is injured is entitled to compensation only if he can show negligence on the part of the research worker or his team. Since one of the purposes of medical research is to explore the unknown and to discover whether there are any unforeseen or unforeseeable consequences of what is being investigated, accidents may occur despite the highest level of competence of the investigators. In the absence 